\title{
Preliminary Results on the Use of Magnetic Techniques on the Study of the Granite Aureoles
}

\author{
Aziz M. KAFAFY \\ Department of Geology, Faculty of Science, University of Tanta, Tanta, Egypt
}

(Received February 2, 1987; Revised June 22, 1987)

\begin{abstract}
The thermal effect of the granite emplacement on the surrounding country rocks has been studied by the use of three magnetic techniques: magnetic susceptibility, isothermal remanent magnetization and Curie point. This effect would sometimes produce metasomatic reactions which yields new ferromagnetic components in the surrounding country rocks. The study indicates that the magnetic techniques are sensitive to these thermal alterations which change the magnetic mineralogy and can be used to determine the limits of the contact aureoles.
\end{abstract}

\section{Introduction}

Magnetic techniques can be used as a tool to estimate the granite aureoles. Ferromagnetic minerals are sensitive to deformational changes and therefore the thermal changes within the contact aureoles can be precisely estimated using the different magnetic techniques.

The magnetic susceptibility $(X)$ is defined as the constant of proportionality between the intensity of induced magnetization and the strength of the applied field. KAFAFY $(1981,1983)$ has drawn attention to the use of magnetic susceptibility to draw the contact aureoles of the granite.

The isothermal remanent magnetization (IRM) reflects the differences in magnetic susceptibility and coercivity and can be used to distinguish the presence of Ti-poor titanomagnetites and Ti-poor ilmenohaematites. The magnitude of saturation magnetization of haematite is much less than that of magnetite. Titanomagnetite and maghemite saturate in fields of 0.01-0.1 T, while haematite does not saturate below fields of 1-3 $\mathrm{T}$. If the magnetizing field is increased the remanence becomes constant (saturated) before $1 \mathrm{~T}$ in magnetite but continues to increase at higher fields in haematite. The study of IRM acquisition before and after heating specimens (KAFAFY, 1985) can indicate change in the ratio of haematite to magnetite if chemical changes occurred.

The Curie point technique is based on the idea that each magnetic mineral of specific composition has a unique Curie temperature (OZIMA and OZIMA, 1964; BANERJEE and O'ReILly, 1967; HedLey, 1968; MERRILl, 1970; MUllins, 1977) so that the Curie point can be used to determine the precise composition within the titanomagnetites (ÖZDEMIR and O'REILLY, 1981; KEEFER and SHIVE, 1981) and 
ilmenohaematites (DUFF, 1979).

The samples used in this study were originally collected for the purpose of the study of palaeomagnetism and anisotropy of magnetic susceptibility. Cores were drilled in the field and oriented using the sun compass. Specimens of $2.5 \mathrm{~cm}$ diameter and $2.2-2.3 \mathrm{~cm}$ length were sliced from the cores. The magnetic susceptibility was measured in two steps, firstly by measuring the initial (bulk) susceptibility using the susceptibility bridge (COLLINSON, 1983) which is capable of measuring diamagnetic and paramagnetic rocks with susceptibilities as low as $1 \times 10^{-5}$ mass S.I. units. Secondly the anisotropy of magnetic susceptibility was measured using a low field torque meter which is modified after STONE (1963). The magnetic susceptibility is calculated as $\left(K_{1}+K_{2}+K_{3}\right) / 3$ (NAGATA, 1961) where $K_{1}, K_{2}$ and $K_{3}$ are the maximum, intermediate and minimum orthogonal axial magnitudes. IRM acquisition was carried out using magnet which can attain a maximum field of $0.7 \mathrm{~T}$. Curie point was measured using thermomagnetic balance with air-tight chamber for heating in a magnetic induction of $0.457 \mathrm{~T}$ at a vacuum of $1.3 \times 10^{-2} \mathrm{~Pa}\left(10^{-4}\right.$ torr $)$ or less. Specimens were heated to $700^{\circ} \mathrm{C}$ with a current of $2.6 \AA$.

The study was carried out on the Um Hombos granite diapir and country rocks in the Precambrian belt of the central Eastern Desert of Egypt (Fig. 1). The pluton (8 $\left.\mathrm{km}^{2}\right)$ is oval-shaped and composite, its longer axis $(3.2 \mathrm{~km})$ trends E-W and shorter axis $(2.2 \mathrm{~km})$ trends $\mathrm{N}-\mathrm{S}$. Petrology, structure and tectonic effect of the diapir was described by AKAAD and NOWEIR (1972). It is considered as one of the phase II Younger Granites of the Egyptian Precambrian rocks (AKAAD et al., 1979). The pluton is divided into two distinct parts, an inner core consisting of muscovite granite and outer ring of porphyritic biotite granodiorite. The contact between the two parts is sharp and distinct. The granite was emplaced in older country rocks consisting of metasediments and metavolcanics (Hammuda Formation and Muweilih Formation) pertaining to the Abu Ziran Group (AKAAD and NowEIR, 1969), and serpentinites. The contact between the granite and its enveloping country rocks is irregular, but knife-sharp. The principal structural features of the diapir are the foliation and fracture system, particularly in the outer porphyritic granodiorite ring. Tectonic effect of the diapir resulted in southward deflection of the belt of metasediments, elimination of certain metasedimentary horizons by thrusting and bending of the metasediments into conformity with the granite boundaries. The inflation of the diapiric body has resulted in a compressional effect upon the surrounding rocks particularly at the northeastern borders of the diapir where we have samples.

\section{Results and Discussion}

Samples were collected at eighteen sites (108 cores) from the granite and the surrounding country rocks in a traverse extending SW-NE from the granite interior to a distance of $\mathrm{Ca} 2 \mathrm{~km}$ from the granite borders (Fig. 1). Sampling sites can be grouped into three distinct areas: area a (including sites 1-6) from the granite interior to the peripheries, area $b$ (sites 7-12) from the peripheries to a distance of $1.1 \mathrm{~km}$ and area c (sites 13-18) further than $1.1 \mathrm{~km}$ away from the granite. The border between 


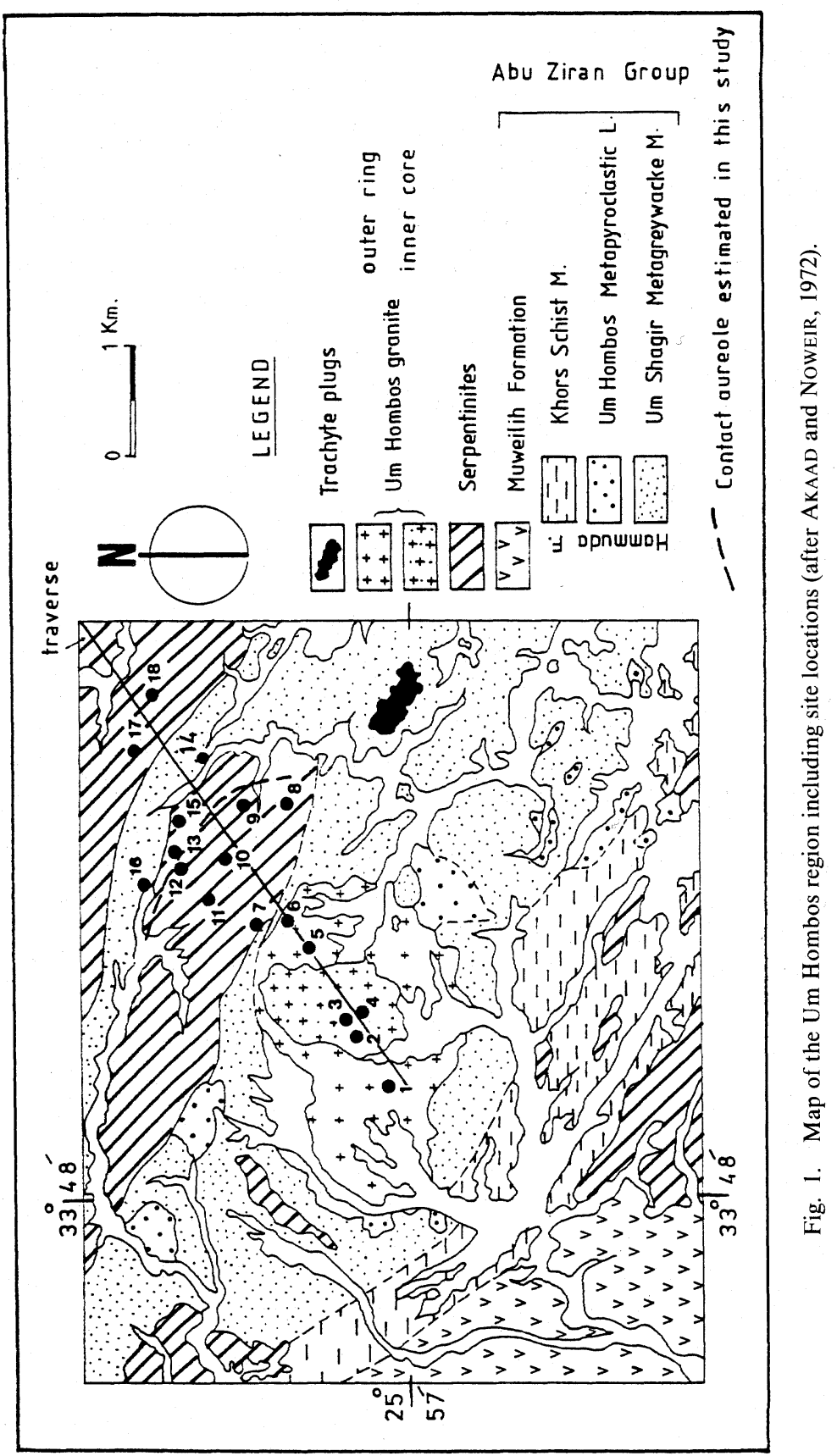


area $b$ and $c$ marks the end of compressional effect of the granite where the granite was apparently able to compress its northern envelope outward in an even manner normal to the original trend of the serpentinite mass.

The magnitude of the magnetic susceptibility is different in each of the three sampling areas (Table 1). In area a, the $X$ values range between $1.1 \times 10^{-3}$ and $4.9 \times 10^{-3}$ mass S.I. units and higher values are reported near the granite borders. In area $b$, the susceptibility is much less than that in a; varying from $1.2 \times 10^{-5}$ to $5.9 \times 10^{-4}$ mass S.I. units which reflects change in the quantity and/or quality in the magnetic minerals present. In area c, the $X$ becomes higher once again $\left(1.8 \times 10^{-4}-8.2 \times 10^{-4}\right.$ mass S.I. units) but weaker than that in area a. This change in magnetic susceptibility from the granite to the end of the traverse would indicates some changes in the magnetic components during the metasomatic reactions accompanying the granite emplacement. Field observation in the three areas of sampling did not prove mineral alterations.

The second technique conducted to confirm this assumption is the IRM acquisition (Fig. 2) which has been carried out on 18 samples (one sample is from each site). The IR M curves in area a showed an early saturation in weak fields $(0.1 \sim 0.2 \mathrm{~T})$ with steep slope indicating that the dominant magnetic mineral is magnetite. This is contrasted with the behaviour in area $b$ (less susceptible sites) where no saturation was achieved in fields up to $0.7 \mathrm{~T}$. This indicates that haematite is dominant. The only exception is site 7 (near the granite peripheries which gave magnetite curve). Area $c$ has magnetite IRM curves but with less magnitude of induced remanence than that in area a. Sample 13 gave a curve which is a composite of both the haematite and magnetite curves, but magnetite must be abundant since it has the higher saturation magnetization. The resemblence between the results obtained from both the magnetic susceptibility and IRM methods indicates the validity of magnetic techniques for the identification of the main ferromagnetic components.

Curie point measurements have been also carried out on 12 representative samples constituting the whole traverse of sampling areas (Fig. 3). The thermomagnetic curves for area a are for magnetite where their Curie points are between 535

Table 1. Distribution of magnetic susceptibility in localities a, b and $\mathrm{c}$ of the studied area (in mass S.I. units).

\begin{tabular}{|c|c|c|c|c|c|}
\hline \multicolumn{2}{|c|}{ Area a } & \multicolumn{2}{|c|}{ Area $b$} & \multicolumn{2}{|c|}{ Area c } \\
\hline $\begin{array}{l}\text { Site } \\
\text { No. }\end{array}$ & $X$ & $\begin{array}{l}\text { Site } \\
\text { No. }\end{array}$ & $X$ & $\begin{array}{l}\text { Site } \\
\text { No. }\end{array}$ & $X$ \\
\hline 1 & $1.1 \times 10^{-3}$ & 7 & $5.9 \times 10^{-4}$ & 13 & $1.8 \times 10^{-}$ \\
\hline 2 & $2.6 \times 10^{-3}$ & 8 & $6.3 \times 10^{-5}$ & 14 & $6.6 \times 10^{-}$ \\
\hline 3 & $1.6 \times 10^{-3}$ & 9 & $2.8 \times 10^{-5}$ & 15 & $8.2 \times 10^{-4}$ \\
\hline 4 & $4.9 \times 10^{-3}$ & 10 & $1.2 \times 10^{-5}$ & 16 & $3.2 \times 10^{-4}$ \\
\hline 5 & $4.1 \times 10^{-3}$ & 11 & $3.1 \times 10^{-5}$ & 17 & $3.1 \times 10^{-}$ \\
\hline 6 & $4.8 \times 10^{-3}$ & 12 & $1.9 \times 10^{-4}$ & 18 & $2.9 \times 10^{-6}$ \\
\hline
\end{tabular}


(a)
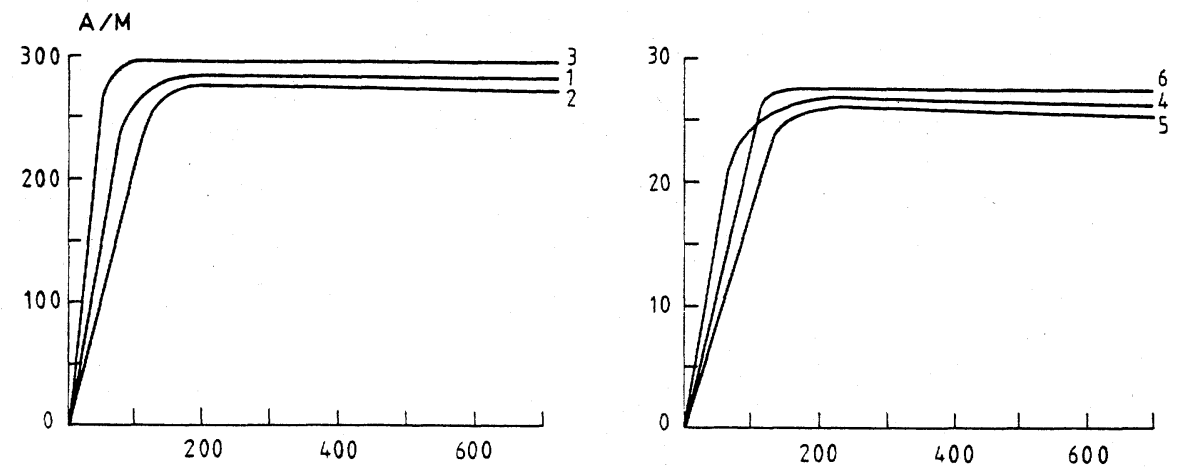

(b)
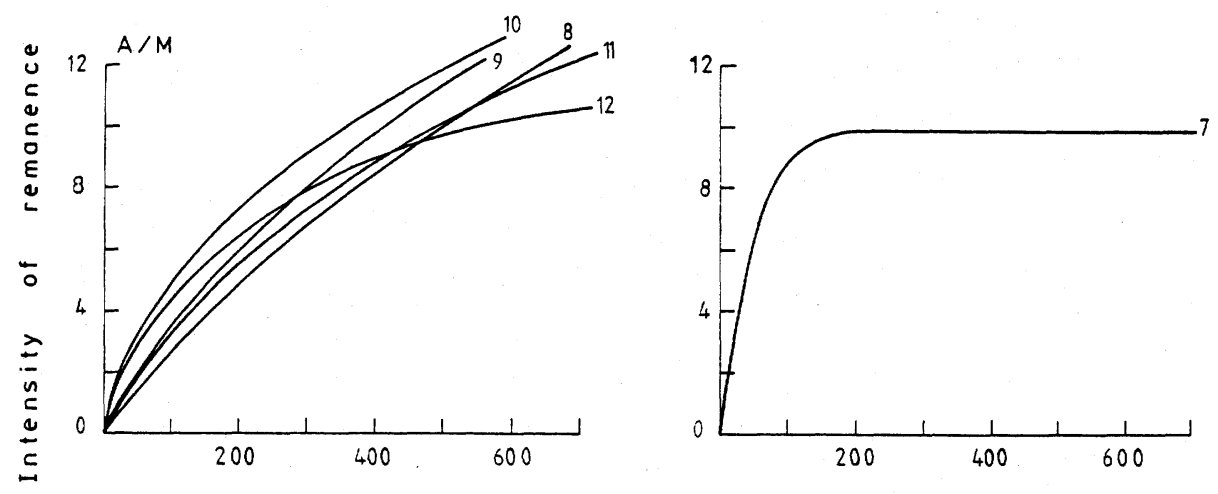

(c)
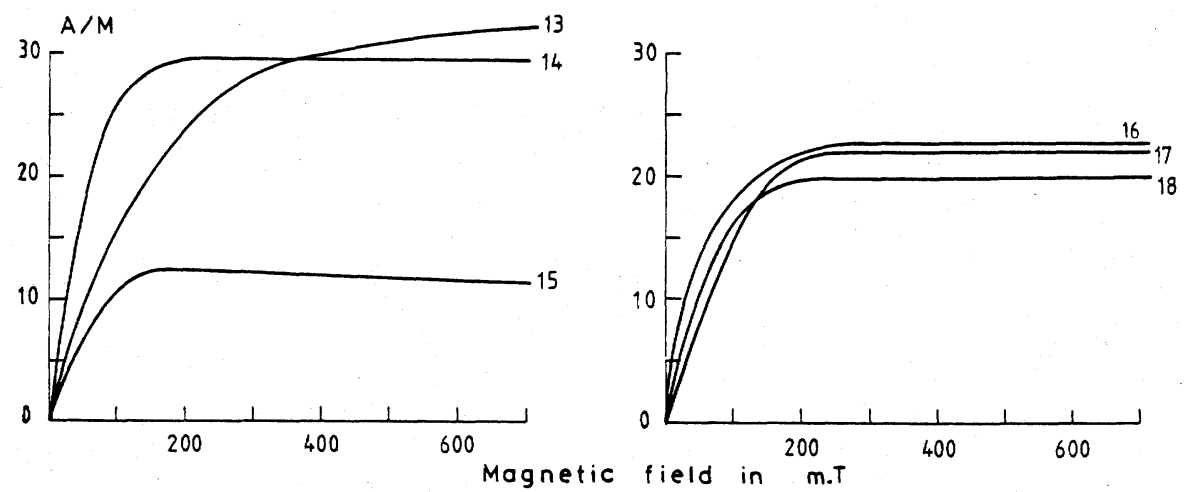

Fig. 2. Isothermal remanent curves for areas $a, b$ and $c$ of the study region. Numbers are sample numbers, early saturation indicates magnetite whilst non saturation indicates haematite. 
(a)

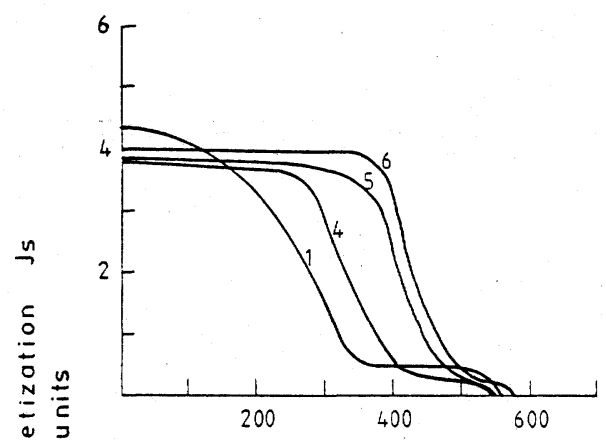

(c)

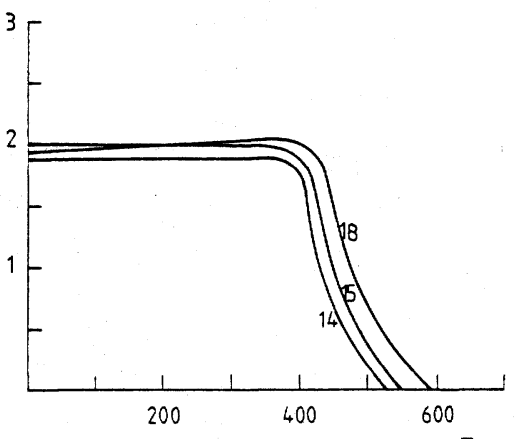

(b)
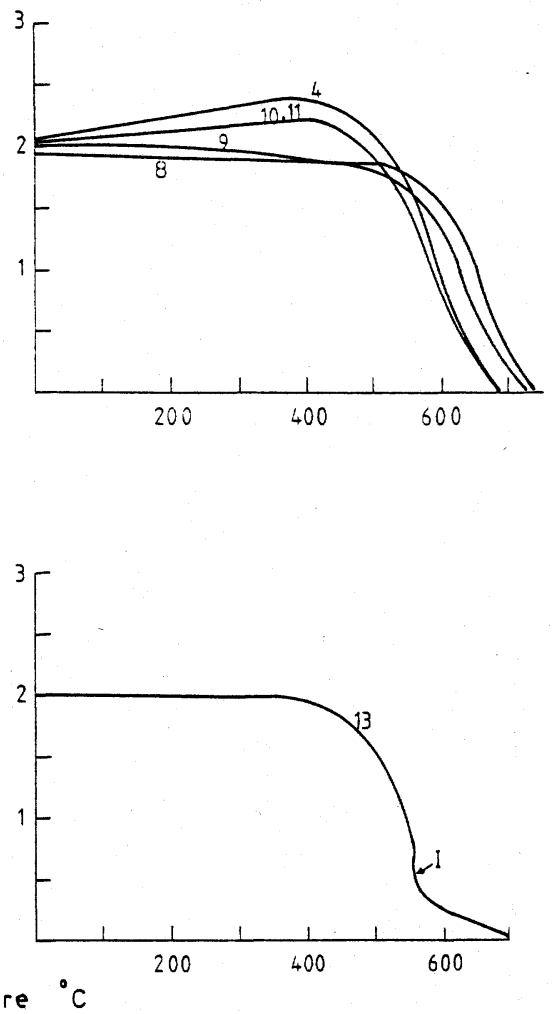

Fig. 3. Thermomagnetic curves for areas $\mathrm{a}, \mathrm{b}$ and $\mathrm{c}$ of the study region.

and $580^{\circ} \mathrm{C}$ (BANERJEE and O'REILLY, 1967; ISHIKAWA, 1967); sample 1 has a curve for Ti-rich titanomagnetite exsolving to form relatively pure magnetite (TARLING, 1983). Area b samples show different and variable curves, but they all indicate the occurrence of haematite. Some samples also flatten at higher applied fields (samples 10 and 11, DUFF, 1979). The haematite samples show various shapes of thermomagnetic curves because the applied field is not enough to saturate these samples. The thermomagnetic curves for area $\mathrm{c}$ are all for magnetite, except for sample 13 which contains both magnetite and haematite. The point of inflation (I) defines the magnetite Curie temperature (GROMME' et al., 1979; MOSKOWITZ, 1981), and the curve is dominated by magnetite which has the higher saturation magnetization.

The results obtained by the magnetic techniques indicate that the granite diapir is rich in magnetite and the older country rocks originally contained magnetite as the main magnetic component. The granite emplacement has resulted in a thermal 
metasomatic effect at the surrounding country rocks up to a distance of $1.1 \mathrm{~km}$ (area b) where the originally formed magnetite of the country rocks was converted to haematite during an oxidation reaction (magnetite can be altered to haematite in igneous rocks in temperatures $>550^{\circ} \mathrm{C}$, TARLING, 1983 and others). Strongly in favour with this assumption is the unique feature of sample 7, which has magnetite curve. This sample lies at the immediate contact with the granite and may perhaps, represent the original magnetite content of the country rocks. This is also the reason why it has a value of $X$ similar to those of area c. The contact effect of the granite is almost negligible at a distance of $1.1 \mathrm{~km}$ (area c) since the original magnetite of the country rocks takes place. Thus the boundary of the granite aureole can be drawn approximately around this distance based on rock magnetic evidences.

\section{Conclusion}

The results reported in this study are only preliminary but promising. More sampling and opaque mineralogical studies would be needed to confirm the general applicability of this idea. However, the change in magnetic mineralogy was detected in this study in the magnetic susceptibility, IRM and Curie point measurements which suggests the sensitivity of the techniques used. A distance of about $1.1 \mathrm{~km}$ from the granite borders could, thus, be used as an estimate of the contact aureole. The only difficulty of this technique is in the use of Curie point technique due to the possibility of chemical alterations which may destroy the minerals before they reach their Curie temperatures; e.g., goethites and pyrrhotites give apparent Curie temperature as they decompose, and other iron-bearing minerals may undergo chemical changes resulting in the formation of new magnetic minerals. It is concluded that the three magnetic parameters can reveal situations in and around the contact aureoles surrounding the granite plutons.

A research grant was presented to the author by the Binational Fulbright Commission of the United States of America. This work was made possible by the use of various instruments of the Department of Geology, University of Texas at Arlington, and I would like to acknowledge Professor Brooks B. Ellwood for giving these facilities to the work. I am grateful to an anonymous reviewer whose constructive criticisms of the earlier manuscript was very helpful in revising this paper.

\section{REFERENCES}

AKAAD, M. K. and A. M. NowEIR, Lithostratigraphy of the Hammamat Um Seleimat district, Eastern Desert, Egypt, Geol. Surv. Egypt, 3, 1-38, 1969.

AKAAD, M. K. and A. M. NoweIr, The Um Hombos granite diapir, Eastern Desert, Egypt, Proc. 12th Arab Sci. Week Damascus, 2, 29-45, 1972.

AKaAD, M. K., A. M. Noweir, and H. Kotb, Geology and petrochemistry of the granite association of the Arabian Desert orogenic belt of Egypt between latitudes $25^{\circ} 35^{\prime}$ and $26^{\circ} 30^{\prime}$, Delta J. Sci., 3(1), 107-151, 1979.

BanerJee, S. I. and W. O'ReILly, The behaviour of ferrous ions in iron-titanium spinels, J. Phys. Chem. Solids, 28, 1323-1335, 1967. 
Collinson, D. W., Methods in Palaeomagnetism and Rock Magnetism, 500 pp., Chapman and Hall, London, 1983.

Duff, B. A., Peaked curves for haematite-bearing rocks and concentrates, Phys. Earth Planet. Ints., 19, $1-4,1979$.

Gromme', S., E. A. Mankinen, M. Marshall, and R. S. Coe, Geomagnetic paleointensities by the Thellier's method from submarine pillow basalts: effects of sea floor weathering, J. Geophys. Res., 84, 3553-3575, 1979.

HedLey, I. G., Chemical remanent magnetization of the $\mathrm{FeOOH}, \mathrm{Fe}_{2} \mathrm{O}_{3}$ system, Phys. Earth Planet. Ints., 1, 103-121, 1968.

IshikaWA, Y., Magnetic properties of a single crystal of $\mathrm{Fe}_{2} \mathrm{TiO}_{4}$, Phys. Letters, 24(A), 725-727, 1967.

Kafafy, A. M., Magnetic fabric studies of the aureoles of some British granites, Ph.D. thesis, Univ. Newcastle upon Tyne, England, 511 pp., 1981.

KAFAFY, A. M., The magnetic susceptibility anisotropy of the Fawakhir granite and its metamorphic aureole, Eastern Desert, Egypt, Delta J. Sci., 7(2), 593-637, 1983.

KafaFY, A. M., Paleomagnetism and magnetic fabric of the Hammamat Group, Eastern Desert, Egypt, Geol. Surv. Egypt, 1985 (in press).

Keefer, C. M. and Shive, P. N., Curie temperature and lattice constant reference contours for synthetic titanomaghemites, J. Geophys. Res., 86, 987-998, 1981.

MerRiLl, R. T., Low temperature treatments of magnetite and magnetite-bearing rocks, J. Geophys. Res., 75, 3343, 3349, 1970.

Moskowitz, B. M., Methods for estimating Curie temperatures of titanomaghemites from experimental $J s-T$ data, Earth Planet. Sci. Lett., 53, 84-88, 1981.

MuLLins, C. E., Magnetic susceptibility of the soil and its significance in soil science-a review, J. Soil Sci., 28, 223-246, 1977.

Nagata, T., Rock Magnetism, 2nd Ed., 350 pp., Maruzan, Tokyo, 1961.

ÖZDEMIR, Ö. and W. O'REILLY, High temperature hysteresis and other magnetic properties of synthetic monodomain titanomagnetites, Phys. Earth Planet. Ints., 25, 408-418, 1981.

OzImA, M. and M. OzIMA, Acquisition mechanism of TRM-low temperature characteristics of TRM and magnetization of some granites, Ann. Prog. Rep. Rock Magn. Res., Group. Japan, 21-29, 1964.

STONE, D. B., Anisotropic magnetic susceptibility measurements on a phonolite and on a folded metamorphic rock, Geophys. J. R. Astr. Soc., 7, 375-390, 1963.

TARling, D. H., Palaeomagnetism, 379 pp., Chapman and Hall, London, 1983. 